\section{Agenesis of Corpus Callosum}

John E. Mendoza

Department of Psychiatry and Neuroscience, Tulane Medical School and SE Louisiana

Veterans Healthcare System, New Orleans, LA, USA

\section{Definition}

A developmental defect in which either all or part of the corpus callosum fails to develop.

\section{Current Knowledge}

Agenesis can result from various etiologies, including genetic predisposition, chromosomal abnormalities, or intrauterine trauma, such as infection. When present, this condition is commonly associated with other neuroanatomical anomalies, metabolic disturbances, and/or neurobehavioral deficits. The latter might include mental retardation, seizures, motor deficits, and psychiatric disturbances. However, some patients may be relatively asymptomatic, the callosal defect being discovered only serendipitously late in life. The latter is more likely to occur when the agenesis is not accompanied by other neurological or metabolic defects. Whereas "disconnection syndromes" are routinely present following surgical commissurotomy for intractable epilepsy, they are generally not present with agenesis.

\section{References and Readings}

Aicardi, J., Chevrie, J.-J., \& Baraton, J. (1987). Agenesis of the corpus callosum. In P. J. Vinken, G. W. Bruyn, \& H. L. Klawans (Eds.), Handbook of clinical neurology (Vol. 50, pp. 149-173). New York: Elsevier.

Marszal, E., Jamroz, E., Pilch, J., Kluczewska, E., Jablecka, H., \& Krawczyk, R. (2000). Agenesis of the corpus callosum: Clinical description and etiology. Journal of Child Neurology, 15, 401-405.

Zaidel, E., \& Iacoboni, M. (2003). The parallel brain: The cognitive neuroscience of the corpus callosum. Cambridge, MA: MIT Press. 